\title{
Nutritional Comparisons of milk from two Cow Specie and Local Preparations of Soya milk drinks
}

\author{
${ }^{1,2}$ Salau, Rasaq Bolakale \\ ${ }^{1}$ (Chemometrics research, Dept. of Chemistry, Universiti Teknologi Malaysia, 81310 UTM Skudai, Johor, \\ Malaysia) \\ ${ }_{2}^{2}$ (Department of chemistry, Federal University of Technology, P M B 65, Minna, Nigeria)
}

\begin{abstract}
Samples of raw milk were expressed from two species (Sokoto gudalli and White fulani) of female cows while fresh soya milk was prepared from soaked grinded soya seeds. Controlled application of heat was applied to all samples up to pasteurization standard and labeled as heated samples. Results of the proximate composition of the samples show significant differences $(P<0.05)$ only in \% average crude fat $(4.20$ and 2.10$)$ and fibre contents (nil and 2.40) respectively in (Cow and Soya milk preparations).The essential elements contents in both soya and cow milk are comparable. The values in the case of cow samples are slightly higher. There is significant presence of manganese $(2.24+0.01 \mathrm{mg} / 100 \mathrm{~g})$ in soya milk preparations. Manganese is not detected in cow milk samples. Similarly, Copper could not also be detected in both soya and Cow Milk samples. Overall observation points the fact that soya milk which is cheaper, more available and simpler in processing could be a better substitute to cow milk. The nutritional wealth of soya milk as an alternative to cow milk can be exploited as a veritable tool to combat the challenges of poverty, hunger and malnutrition towards achieving the millennium development goal.
\end{abstract}

Keywords- Controlled heat, essential elements, nutritional wealth, proximate composition, substitute,

\section{INTRODUCTION}

Milk often connotes an off-white nutritious liquid conjectured from the off-whitish natural fluid secreted by female mammals from the mammary gland purposely to nourish their young ones. Earlier studied milk composition[1] shows that milks contain all the main food classes: fats, proteins, carbohydrates, minerals as well as vitamins all dispersed in water. Furthermore, recent study on the nutritional impacts of milk by Ranganathan et al[2], further buttress the indispensability of milk in human nutrition. Epidemiological studies by Petti et al[3]; Ranganathan et al[2] and Keiko et al[4] have proven the health benefit of milk as containing low incidence of dental caries in children that drink more milk.

The World Health Organization (WHO) campaign for exclusive breast feeding of infants for the first six months further lends credence to the absolute nutritional values of milk. Milk therefore is an indispensable substance as far as food and feeding are concerned. Occasions often arise that breast milk could not sufficiently meet up with the human needs, milk from other mammal sources are resorted to. Hence, other infant milk formulas as well as that for the adult are obtained from cows.

Increasing demand for milk has prompted the need to extend search for its substitute not only in other mammals but also from plant source. One of the plant sources that attracted focus of people is soya .Soya plant is commonly available. It grows well in wide range of soil, with optimum growth in moist alluvial soils with a good organic content. Soya milk as animal milk substitute has been gaining popularity in the dairy industry and also widely consumed [5] by individuals with history of intolerance for cow milk.

Since both soya and cow milk consumptions are now gaining acceptance, it is pertinent to establish some facts about their nutritional significance. The common local practice is that soya milk preparation has to be boiled before consumption. Similarly, Cow milk too required heating (pasteurization) before consumption. This paper, therefore, is aimed at comparatively determining the proximate nutrient composition of both locally prepared soya milk and the milk locally sourced from two selected cow specie (Sokoto gudali and white fulani) both at fresh and heated conditions.

\subsection{Sample collection and treatment}

\section{EXPERIMENTAL}

Raw milk was collected from two specie of cow namely; Sokoto gudali and White fulani in the Fulani Cattle farmer settlement around Bosso Estate in Bosso Local Government area of Niger State, North Central Zone of Nigeria. Milking processes were done on subjected cows immediately the dawn set in around $5.30 \mathrm{Hr}$ G.M.T.

The milk expressions from the female cow breasts were done with initial stimulations to let down milk by allowing infants cow to suck for few seconds. The fresh milk samples obtained were then taken, for further 
processing, to the chemistry laboratory of Federal University of Technology, Minna, Nigeria. The fresh milk are labelled as Fresh Cow Milk (FC1 and FC2 respectively for Sokoto gudali and White fulani ).Heat was applied to the milk in pasteurization manner [6]. The heated sample are labeled as (HC1 and HC2).

The soya beans were obtained from Minna Central Market, Niger State, north Central, Nigeria. Sizeable quantities were soaked overnight with tap water to replicate as they are locally prepared and consumed by the public. The swollen and softened beans were passed to a pre-cleaned grinding machine. More cold water was added to further homogenize the mixture. A clean white cloth was then used to squeeze out the milk Content. This milk sample is labeled as fresh Soya Milk (FSM). The freshly squeezed milk was then heated close to boiling and labeled as heated soya milk (HSM).

\subsection{Proximate analysis}

The proximate analysis was carried out to determine the crude fat, protein and fibre content as well as ash, moisture, carbohydrate and energy content of samples. The crude fat content was obtained using soxhlet apparatus and extracting with petroleum ether as cited in Association of Official Analytical Chemists' methods [7]. The Nitrogen content was determined by micro Kjeldahl method as described in [8]. The Nitrogen content was converted to protein by multiplying by a factor of 6.25.Carbohydrate was determined by difference. The moisture, ash and fibre content determinations were carried out according to the Association of Official Analytical Chemists' methods [7].

\subsection{Digestion of sample for mineral analysis}

Wet ashing procedure was followed in digesting the samples. $2 \mathrm{~g}$ of each of the dried samples was weighed into a beaker. $20 \mathrm{~cm}^{3}$ of a mixture of per chloric and nitric acid ratio 1:4 was measured and added to the sample in the beaker. A few bead stone was added as anti-bumping agent.

The mixture was heated with a hot plate at a temperature of $200^{\circ} \mathrm{C}$. It was then swirled with occasional addition of nitric acid until the digest was clear solution. This was allowed to cool and was filtered through acid wash filter paper into a $100 \mathrm{~cm}^{3}$ volumetric flask and was made up to the mark. The filtrate was transferred into a polyethylene container temporarily before subsequent determination of the mineral content.

\subsection{Instrumental determination of minerals}

Atomic absorption spectrophotometer (BUCK scientific ACCUSYS 211 model no210 VGP) was used to determine Calcium (Ca), Zinc ( $\mathrm{Zn})$, Magnesium $(\mathrm{Mg})$, Manganese $(\mathrm{Mn})$, Copper $(\mathrm{Cu})$ and Iron $(\mathrm{Fe})$. Flame photometer (model JENWAY PFP7) was used to determine the concentration of Potassium (K) and Sodium $(\mathrm{Na})$.

\subsection{Colorimetric determination of phosphorus}

Colorimetric method involving PhosphoVanado Molybdate complex was used to quantify the phosphorous present in the sample. Ammonium vanadate and Ammonium molybdate reagent solutions were prepared. Ammonium vanadate solution was prepared by dissolving $0.625 \mathrm{~g}$ of ammonium vanadate, $\mathrm{NH}_{4} \mathrm{VO}_{3}$ in $125 \mathrm{~cm}^{3}$ of hot distilled water and followed by the addition of $5 \mathrm{~cm}^{3}$ of concentrated nitric acid. The solution was diluted with distilled water to reach the $250 \mathrm{~cm}^{3}$ volumetric flask. The Ammonium molybdate reagent solution was prepared by dissolving $12.5 \mathrm{~g}$ of ammonium molybdate crystals, $\left(\mathrm{NH}_{4}\right)_{6} \mathrm{Mo}_{7} \mathrm{O}_{24}, 4 \mathrm{H}_{2} \mathrm{O}$ in warm distilled water.

The solution was then diluted with distilled water to reach the $250 \mathrm{~cm}^{3}$ volumetric flask.

$20 \mathrm{~cm}^{3}$ of each of the sample digests was transferred to $250 \mathrm{~cm}^{3}$ volumetric flask followed by addition of $100 \mathrm{~cm}^{3}$ of distilled water, $40 \mathrm{~cm}^{3}$ of each of the prepared reagents and then made up to the $250 \mathrm{~cm}^{3}$ mark of the flask. Standard concentrations of potassium di-hydrogen phosphate containing dilute nitric acid and same quantities of the two reagents. Absorbance, first with blank and then standards are determined at $465 \mathrm{~nm}$ wavelength using $1 \mathrm{~cm}$ cell. Phosphorus concentrations in the samples are obtained using calibration curve.

\section{RESULTS AND DISCUSSION}

\subsection{Food Proximate Composition}

Table 1 reveals the values of the food content of the studied samples. The ash contents of the milk samples are quite comparable. This is an indication that all the samples investigated have mineral-nourishing capabilities. However it is quite apparent that the absolute value of that of cow milk $(0.90 \%)$ is higher than that of soya $(0.55 \%)$. Both are within the range reported by [9], for whole raw milk of Horro cow specie in Guto Wayo (0.70) and Bila Sayo (0.70) districts of Ethiopia. The major contrasts in the food proximate content are the values obtained for the fat contents. This significant difference showed cow milk to be about two times richer in fat content than soya milk preparation. Fat content of food is the major contributor to the energy value of food. This implies that cow milk is more energy yielding than soya milk preparation. The low fat content of 
the soya milk preparation is a health advantage. This is because of less risk of cholesterol elevation action in the bloodstream. From studies [10], fats of animal origin rather plant; usually contain some high saturated fatty acid implicated for raising blood cholesterol. The presence of high levels of cholesterol in the bloodstream may form some deposits in the arteries in a fatty nature. These deposits may slow or block the flow of blood through the body and possibly causing heart attack or stroke.

\subsection{Mineral composition}

Generally, averages of both milk preparation samples contain comparable mineral elements in due proportions. Copper element was not detected in both milk preparations. Manganese was detectable in soya milk preparation samples. Manganese is an essential trace element required in the body for the nourishment of the brain and nerves in the nervous system [11]. It also plays an active role in reproduction, digestion and metabolism of amino acids, carbohydrates (sugar), cholesterol and fat as well as the skeletal structure formation [12]. The manganese average value of $2.24 \mathrm{mg} / 100 \mathrm{~g}$ is equivalent to $5.77 \mathrm{mg} / 250 \mathrm{~mL}$ of highly concentrated commercial soya milk preparation. The figure is close to the limit of Required Dietary Allowance (RDA) 2.50 $5.00 \mathrm{mg}[13]$. Adequate presence of manganese accords the soya milk preparation a higher level of preference.The two cow species: Sokoto gudali and White Fulani, have comparable values of the mineral contents determined except in sodium, calcium and phosphorus where White Fulani contains greater values. This implies that White Fulani contains more adequate strong bone and teeth formation mineral elements $(\mathrm{Ca}$ and $\mathrm{P})$.The less value of sodium in Sokoto gudali shows that it is less likely to contribute to high blood pressure.

The application of heat in the milk preparation does not make appreciable changes in values of the mineral content compared to the value obtained from fresh ones. However, the average result obtained for all the three samples showed that hotter state of the milk preparations is accompanied with increased content of sodium. This observation agrees with [13].

The average value of sodium to potassium ratio ( $\mathrm{Na}: \mathrm{K}$ ) in both cow and soya milk preparations are comparable and within the permissible value of less than 1[15] (NRC, 1990). Sodium to potassium ratio is necessary in discussing healthy food. Both sodium and potassium are essential minerals required for the maintenance of the fluid balances in the body. Much more potassium than sodium or ratio value less than 1 , is desirable. This proportion helps in promoting normal blood pressure. A Na: K ratio of more than 1 can lead to hypertension. Similarly, calcium to phosphorus ratio status is also important in evaluating the nutritional feature of foods. Both elements are bone forming materials. The average calcium to phosphorus ratio obtained in the cow and soya milk preparations are 0.89 and 0.83 respectively. This is not far from the dietary reference intake (DRI) for health safety of $\mathrm{Ca}$ to $\mathrm{P}$ ratio permissible within 1-1.3 [16].The phosphorus value in cow milk is similar, baring the contribution of other ingredients, to the one obtained in fura da nunu, a local milk food in Minna as reported by [17].

Table 1. Mean proximate composition $(\%)$ of cow and soya milk preparations

\begin{tabular}{|c|c|c|c|c|c|c|c|c|c|c|c|}
\hline $\begin{array}{l}\text { Food } \\
\text { content }\end{array}$ & FC1 & HC1 & FC2 & FC2 & FS & HS & $\mathbf{C}_{\text {ave }}$ & $S_{\text {ave }}$ & t-cal & t-crit & sig \\
\hline Ash & 1.20 & 0.60 & 1.00 & 0.80 & 0.60 & 0.50 & 0.90 & 0.55 & 2.12 & 2.78 & $\mathrm{~N}$ \\
\hline Carbohydrat & & & & & & & & & & & \\
\hline e & 4.30 & 3.50 & 5.60 & 5.00 & 4.30 & 4.80 & 4.60 & 4.55 & 2.57 & 2.78 & $\mathrm{~N}$ \\
\hline Crude fat & 4.90 & 5.20 & 3.10 & 3.60 & 2.10 & 2.10 & 4.20 & 2.10 & 4.83 & 2.78 & S \\
\hline Crude fibre & ND & ND & ND & ND & 2.50 & 2.30 & ND & 2.40 & - & - & - \\
\hline $\begin{array}{l}\text { Crude } \\
\text { protein }\end{array}$ & 4.20 & 5.70 & 4.20 & 5.80 & 6.00 & 6.00 & $\begin{array}{l}5.13 \\
85.1\end{array}$ & 6.00 & 2.47 & 2.78 & $\mathrm{~N}$ \\
\hline $\begin{array}{l}\text { Moisture } \\
\text { Energy }\end{array}$ & 85.60 & 85.00 & 85.20 & 84.80 & 84.50 & 84.30 & $\begin{array}{l}5 \\
320 .\end{array}$ & 84.40 & 0.45 & 2.78 & $\mathrm{~N}$ \\
\hline$(\mathrm{KJ} / 100 \mathrm{~g})$ & 325.80 & 348.80 & 281.30 & 316.4 & 252.10 & 260.6 & 81 & 257.05 & 0.23 & 2.78 & $\mathrm{~N}$ \\
\hline
\end{tabular}

Table 2. Essential element content $(\mathrm{mg} / 100 \mathrm{~g})$ of cow and soya milk samples

\begin{tabular}{llllllllllll}
\hline Elements & FC1 & HC1 & FC2 & FC2 & FS & HS & C $_{\text {ave }}$ & $\mathbf{S}_{\text {ave }}$ & t-cal & t-crit & sig \\
\hline Calcium & 125.20 & 111.55 & 148.32 & 151.23 & 126.56 & 89.97 & 134.08 & 108.27 & 2.56 & 2.78 & $\mathrm{~N}$ \\
Copper & ND & ND & ND & ND & ND & ND & - & - & - & - & - \\
Iron & 14.30 & 12.20 & 14.10 & 11.40 & 15.55 & 13.70 & 13.00 & 14.63 & 0.30 & 2.78 & $\mathrm{~N}$ \\
Magnesium & 5.10 & 5.00 & 5.01 & 5.03 & 5.00 & 5.06 & 5.03 & 5.03 & 0.00 & 2.78 & $\mathrm{~N}$ \\
Manganese & ND & ND & ND & ND & 2.23 & 2.25 & - & 2.24 & - & - & - \\
Phosphorus & 143.00 & 125.00 & 170.00 & 165.00 & 145.00 & 115.00 & 150.75 & 130.00 & 1.14 & 2.78 & $\mathrm{~N}$ \\
Potassium & 23.82 & 20.30 & 22.39 & 18.26 & 21.83 & 14.08 & 21.19 & 17.96 & 0.70 & 2.78 & $\mathrm{~N}$ \\
Sodium & 7.08 & 7.68 & 12.15 & 13.03 & 8.60 & 9.17 & 9.99 & 8.89 & 1.09 & 2.78 & $\mathrm{~N}$ \\
Zinc & 20.30 & 20.30 & 20.30 & 18.90 & 14.00 & 13.60 & 19.94 & 13.80 & 2.48 & 2.78 & $\mathrm{~N}$ \\
Na/K ratio & 0.30 & 0.38 & 0.54 & 0.71 & 0.39 & 0.65 & 0.47 & 0.49 & 0.26 & 2.78 & $\mathrm{~N}$ \\
\hline
\end{tabular}




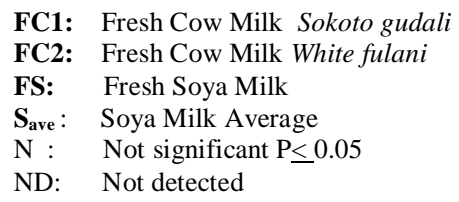

\author{
HC1: Heated Cow milk Sokoto gudali \\ HC2: Heated Cow Milk White fulani \\ HS: Heated Soya Milk \\ $\mathbf{C}_{\text {ave }}$ : Cow Milk Average \\ S: $\quad$ Significant $\mathrm{P}<0.05$
}

\section{CONCLUSION}

This study is able to establish the close nutritional gap between Cow milk and soya milk preparations. The nutritional parameters of the proximate composition and the essential minerals measured in both food samples are comparable. These clearly point to the fact that either of the foods can substitute for each other.

The milk from cow can be a better option in terms of energy or the calorific value as a result of high fat content. Based on this, milk from cow can serve as infant formula in case of dire need to substitute breast milk. However, the milk from cow source is beset with the shortcomings of inherent possibility of raising the blood level cholesterol due to the animal nature of fat it contains. Similarly, fibres were not contained in the milk from cows, thus making the milk lack beneficial role in heathier colon and bowel movement for easy digestion. The non-presence of trace essential element like manganese, within the limit of detection, is also a nutritional defect in cow milk. Manganese played important role in the skeletal formation and metabolism of cholesterol.

In contrast, the milk preparations from soya possess these nutritional parameters which are lacking in the cow milk. The manganese and fibre contents of the milk preparation are adequate and within the required dietary allowance. The healthier nature of the soya milk fat content over shadows its low fat quantity. The fat content of soya milk, according to literature, contains very low saturated fatty acid and hence not likely to raise the level of cholesterol in the blood. In the foregoing analysis, Soya can provide quantitative and qualitative alternative to milk from cow which has been an age-long practice in dairy industries. Soya milk can be prepared locally contrary to the boredom of capital and labor intensive industrial routine of cow milk process. Soya seeds are cheaper and far more accessible and available than time-dependent cattle grooming. It can therefore be advanced that encouragement of the preparation and consumption of soya milk preparations can be a veritable asset to confront the challenges of poverty, hunger and malnutrition as entrenched in the millennium development goal.

\section{References}

[1]. Adeneye J. and Olaloku E. Preliminary findings on composition of milk of White Fulani. Nigerian Journal of Science, 4 (2) 1970. 181-186

[2]. Ranganathan R., Nicklas T. and Berenson G.S. The nutritional impact of dairy product consumption on dietary intakes of adults .J Am Diet Assoc. 105(9), 2005. 1391-400

[3]. Petti S., Simonetti R. and Simonetti D'Arca A. The effect of milk and sucrose consumption on caries in 6-to-11-year-old Italian school children. European Journal of Epidemiology ;13, 1997.659-64.

[4]. Keiko T., Yoshihiro M. and Satoshi S. Intake of dairy products and the prevalence of dental caries in young children. Journal of dentistry 38,2010. $579-583$

[5]. Bahareh H.,Comparison of Nutritional and Chemical Parameters of Soymilk and Cow milk( World Academy of Science, Engineering and Technology,2009)

[6]. NDC. National Dairy Code.(2005) Dairy Processing and Production Regulations- Food inspection system, $4^{\text {th }}$ Edition.

[7]. AOAC.(2005) Association of Official Analytical Chemists. Official method of analysis. Washington D. C.

[8]. Pearson D. and Henry E.The chemical analysis of food. $7^{\text {th }}$ Edition, Churchill Livingstone.1976, ISBN0443014116, 9780443014116

[9]. Alganesh T., Ofodile. L. and Fekadu B. Microbial Quality and chemical composition of raw whole milk from Horro cattle in East Wollega, Ethopia._African Journal on line 2007.Vol 3, No 1

[10]. Simopoulos A., and De Meester F. Editors.. A balanced omega 6/ omega3 fatty acid ratio, cholesterol and coronary heart diseases. World review of nutrition and dietetics. Vol.100. 2009.pp 91. Switzerland,Karger Columbus Concept.

[11]. Nelson,D. and Michael M.. Lehninger Principles of Biochemistry, Third Edition (3 Har /Com ed.). W. H. Freeman. 02-15.2000. pp. 1200. ISBN 1572599316

[12]. Keen C, Ensunsa J , Watson M, Baly D, Donovan S, Monaco M and Clegg M. Nutritional aspects of manganese from experimental studies. Neurotoxicology.; Pub.Med. 20, 1999:213-223.

[13]. USDA Nutrient database for standard reference.2003 USA: USDA; Release 18.

[14]. Orhevba B. The effect of cooking time on the nutritional parameters. Am. J. Food Technol. 6(4), 2011. 298-305.

[15]. NRC. National Research Council. Dietary Reference Intake. (Educational National Academic Press,2005) Washington DC, USA.

[16]. Virpi E., Merja U., Karkkainen, Hannu R., Marika M. Laaksonen, Terhi A., and Christel J. Low calcium: phosphorus ratio in habitual diets affects serum parathyroid hormone concentration and calcium metabolism in healthy women with adequate calcium intake. British Journal of Nutrition, 103, 2010. 561-568

[17]. Salau, Rasaq Bolakale, AbdulKarim Ali Deba and Jimoh Yusuf. Quantification of Iron, Magnesium and Phosphorus contents of selected local dishes in Minna, Nigeria. IOSR Journal of Environmental Science, Toxicology and Food Technology (IOSRJESTFT). ISSN: 2319-2402, ISBN: 2319-2399. Volume 1, Issue 3 (Sep-Oct. 2012), PP 33-36.www.iosrjournals.org 